\title{
La recepción de la traductología latinoamericana en Chequia: inspiraciones temáticas, metodológicas y didácticas
}

Palabras clave: traductología, comunicación intercultural, metodología, traducción cultural, canibalismo.

DOI: $10.4312 /$ ars.11.2.44-55

\section{Introducción}

En las últimas décadas, la traductología ha venido buscando una renovación metodológica en las áreas lingüísticas y culturales marginales y marginadas hasta hace poco (cf. Lambert, 2010), aspecto que abre las puertas a la introducción de las concepciones y temas relegados al segundo plano durante décadas, los latinoamericanos entre ellos, ya sea por una limitada accesibilidad lingüística, ya sea por cierta subestimación de los textos por el público receptor. Sin embargo, la traductología latinoamericana ha venido ganando terreno en la investigación a nivel internacional, emancipándose de sus raíces metodológicas europeas y abriendo temas y problemas nuevos o novedosos no solo para la disciplina misma, sino también otras áreas de investigación, fenómenos que se reflejan entre otras características también en la proliferación de las escuelas y programas universitarios dedicados a la formación de traductores (Vavroušová, 2015a, 16). Estos son los motivos que justifican la importancia de la presentación de los temas y autores en otros ámbitos culturales.

Siguiendo el orden cronológico, el presente texto se centrará en la recepción, presentación y divulgación de los siguientes aspectos, poniendo énfasis en la evolución del pensamiento translativo a partir de la segunda mitad del siglo XX, a partir de los textos publicados en checo en sendas antologías como expresiones generacionales y en la revista Svět literatury ${ }^{1}$. Se intentará reflejar la evolución de los temas estudiados: el de

1 Revista publicada desde 1991, se dedica a las literaturas modernas de Europa y América, con referencias a otras áreas culturales. Pone énfasis en la concepción comparativa de las literaturas para superar las limitaciones del estudio de las literaturas nacionales, basado en los esquemas y conceptos tradicionales. Los miembros del círculo de redacción comparten la idea de que la evolución de las literaturas se lleva a cabo en regiones más amplias más allá de los límites de una sola nación. Además de los contribuyentes checos, la revista cuenta con la colaboración de importantes representantes de la investigación literaria a nivel universal, como por ejemplo Carlos Fuentes, Miguel León Portilla (México), Stephen Greenblatt (Reino Unido), Aage Hansen-Löeve, Gertraude Zand (Austria), 
los escritores traductores/traductólogos, seguido por el surgimiento de la traductología «académica» y sus protagonistas, así como la evolución de las metodologías propias, sin dejar aparte su importancia pedagógica y didáctica en el ámbito centroeuropeo.

\section{Escritores traductores / traductólogos}

Ante todo, durante el siglo XX, varios escritores e intelectuales latinoamericanos han prestado atención a los problemas de traducción. Vavroušová (2015b, 15) cita entre ellos a Jorge Luis Borges, Ricardo Palma, Octavio Paz, Pablo Neruda y Rafael Pombo.

La presencia de los textos de eminentes autores latinoamericanos, quienes ofrecen escritos dedicados a los problemas de traducción en el ambiente cultural checo, se pueden dividir en dos grupos: textos traducidos por una parte, y el análisis de sus concepciones por la otra. Entre los mencionados autores destacan dos protagonistas de la literatura latinoamericana: Octavio Paz y Jorge Luis Borges. ${ }^{2}$

\subsection{Octavio Paz}

\subsubsection{Textos propios del autor}

La revista Svět literatury $(38,2008,173-182)$ publica la traducción del ensayo Traducción: literatura y literariedad (original publicado en 1971) acompañada de una introducción que bajo el título Univerzální pluralita: překlad v myšlení O. Paze (Housková, 2008, 169-172) introduce para el lector checo la visión de la traducción del autor mexicano.

\subsubsection{Metatextos y peritextos}

En sus análisis, M. Housková pone énfasis en varios aspectos del ensayo de Paz: la concepción de la traducción como fenómeno de carácter literario, metafórico, creativo, relegando al segundo plano su visión como operación lingüística (Housková, 2008, 170); la función de la traducción basada en la época dada por el paso de la referencia a la universalidad hacia la referencia a la pluralidad, manifestada en la tendencia a suprimir la otredad por una parte, y por la otra, en el esfuerzo por conservarla,

Graciela Maturo (Argentina), Marc Quaghebeur (Bélgica), Fernando Savater (España), Wasilij Ščukin (Polonia) y otros. (http://sl.ff.cuni.cz [13. 9. 2017]).

2 El panorama sería incompleto sin mencionar el libro de Gabriel Rosenzweig (comp.). Procurando contactos a la literatura mexicana. Alfonso Reyes-Zdeněk Šmíd. Correspondencia (1932-1959). México, D. F.: El Colegio de México, aunque su tema contribuye ante todo a profundizar el conocimiento de la historia de las traducciones de literaturas latinoamericanas en Checoslovaquia durante el período mencionado. 
subrayando que las dos tendencias pueden existir y / o una de ellas puede llegar a ser dominante paralelamente en determinada etapa de la evolución del arte (Housková, 2008, 171).

Al incorporar el texto de Octavio Paz en el contexto de las investigaciones del trasvase, la autora cita a Schleiermacher, Ortega y Gasset, A. Berman y A. L. Venutti; sin embargo, es de extrañar que no lo haya incorporado en la tradición doméstica (checa), fenómeno que destaca ante todo considerando el año de la publicación del original (1971): las deliberaciones de Octavio Paz aparecen casi paralelamente con los trabajos del autor checo Jiří Levý, cuya obra fundamental, Umění překladu (El arte de la traducción) fue publicada en 1963. El análisis de la dicotomía entre la visión de la traducción como fenómeno de carácter creativo por una parte, y como operación lingüística por la otra, ofrece un paralelo entre el ilusionismo/antiilusionismo de la traducción, o doble norma de la traducción, definida por Levý en el año 1963 (Králová et al., 2013, 74-76), donde la visión dinámica de la función de la traducción (conservación/eliminación de la otredad) muestra cierta analogía con la visión del trasvase como elemento unificador de la literatura universal y como fenómeno diversificador de las letras receptoras (Levý [1971], en: Králová et al., 2013, 159-160).

\subsection{Jorge Luis Borges}

\subsubsection{Textos propios del autor}

La presencia del pensamiento traductológico de Borges en el ámbito checo es más amplia: en 1970 salió la versión checa de su ensayo Versiones homéricas (trad. Kamil Uhlír) en la antología Překlad literárního díla [Traducción de la obra literaria]; no obstante, hubo de esperar varias décadas para que se publicara el ciclo de sus conferencias, pronunciadas entre 1967 - 1968 en la Universidad de Harvard bajo el nombre de Ars poetica (trad. Mariana Housková, Mladá fronta, 2005). ${ }^{3}$

\subsubsection{Metatextos y peritextos}

Como es de esperar, es el libro Ars poetica el que ha despertado mayor interés por parte de los especialistas. Sin embargo, no sorprende que los peritextos publicados (por ejemplo, Housková, 2005) dejen de lado el tema de la traducción.

Interesante resulta, sin embargo, la recepción por parte de los investigadores de la traducción incluso fuera del área de las literaturas románicas. Citemos como ejemplo a Kšicová (2011, 1-6), quien lo incorpora con la tradición filosófica y poética de la traducción literaria, poniendo énfasis en la evolución del pensamiento estético a partir 
de los años veinte y treinta del siglo XX. A partir de su propia experiencia de traductora de la literatura rusa, subraya ante todo el énfasis en la relación entre la traducción y la creación propia del traductor y en la justificación de la traducción libre.

Un análisis más sistemático de la concepción de Borges aparece en Šišmišová (2012). La autora destaca ante todo que Jorge Luis Borges comprende la traducción artística como un género especial de la actividad literaria, realizado en un contexto cultural y social, como un acto literario autónomo, y destaca la importancia de la trasferencia cultural.

\section{Traductólogos «académicos» o los que miran el tapiz por el revés}

Como ya se ha señalado, las investigaciones latinoamericanas en el área de la traducción han supuesto un enorme avance en las últimas décadas, emancipándose de sus modelos europeos y elaborando sus propias concepciones y métodos (Vavroušová, 2015a, 8). Sin embargo, hay que tener presente que dados los idiomas de las publicaciones (el español y el portugués), lo que ha sido el motivo de la iniciativa de preparar una antología de estudios dedicados a los problemas teóricos (y a veces prácticos) de la traducción bajo el título Překlad a tlumočení jako most mezi kulturami [Traducción e interpretación como puente entre las culturas] (Vavroušová et al., 2015). ${ }^{4}$

Al analizar la representatividad de los textos incluidos en el libro, hay que tener presente que cada antología forma un conjunto de trabajos inexistente desde los puntos de vista sincrónico y diacrónico, superando los horizontes generacionales de las expectativas sociales y (en este caso) culturales de los autores de los originales y su importancia puede ser diferente de la de los estudios que la componen (cf. Havelka, 2008, 6). Por otra parte, hay que considerar que el origen, la composición y la organización de los textos pueden tener carácter heterogéneo y el potencial interpretativo se somete a nuevos contextos históricos tanto por parte del editor de la antología como por parte de su lector y, en el caso del volumen analizado, se convierte en una confesión generacional de los investigadores más jóvenes. ${ }^{5}$

El libro incluye la traducción de siete textos de especialistas latinoamericanos: Adriana Domínguez Mares (México), Ricardo Silva-Santesteban (Perú), Martha

4 La preparación de la antología fue iniciativa de alumnos del Doctorado en Traductología y del Máster en Traducción del Instituto de Traductología de la Facultad de Filosofía y Letras de la Universidad Carolina, Praga y fue subvencionada por la Facultad.

5 Cabe destacar que el libro no representa el primer encuentro académico checo con la traductología latinoamericana, ya en 2011 se publicó en castellano el artículo de Martha Pulido «La traducción de la historia de la traducción en la formación de traductores» (ed. Králová, 2011). 
Pulido Correa (Colombia), Lourdes Arencibia Rodríguez (Cuba), Célia Luiza Adrades Prado (Brasil), e Iván Pinto Román (Perú), quien se sale del marco del academicismo de los autores al ser jurista de formación y diplomático de profesión. Además, el libro contiene tres textos introductorios, cuyo objetivo es, por una parte, presentar al público lector la selección de los originales (Vavroušová, 2015 b) y resumir la evolución de las investigaciones en el campo de la traducción e interpretación en las respectivas áreas lingüísticas (Vavroušová, 2015b - los países hispanohablantes; Laufková, 2015 - Brasil).

\subsection{Orientación temática de los textos presentados}

Los textos presentados en la antología siguen dos ejes temáticos fundamentales:

- La visión del papel de la traducción / interpretación en la configuración y emancipación de la(s) cultura(s) latinoamericana(s) incluida la visión del papel social / cultural del traductor / intérpete

- Los conceptos propios de la traducción latinoamericana («traducción cultural», «canibalismo»).

\subsubsection{El papel de la traducción / interpretación en la configuración y emancipación de la(s) cultura(s) latinoamericana(s)}

La importancia de la traducción / interpretación para la comunicación entre diversos pueblos (latino)americanos es innegable y se pueden suponer casos anteriores al descubrimiento. Lógicamente, el descubrimiento, la conquista, la colonización y la evangelización de América representaron un gran impulso para la comunicación entre los diversos pueblos, convirtiendo al español en una verdadera lingua franca del continente y contribuyendo en gran medida a la formación del Imperio. Por otra parte, cabe destacar que fueron los traductores quienes ayudaron a conservar al menos las huellas de varias lenguas indígenas (p. ej. Zimmermann, 2012).

Resulta, pues, natural que la antología Překlad a tlumočení jako most mezi kulturami ofrezca al lector checo textos dedicados al papel de la traducción/ interpretación en los albores de la Latinoamérica como la conocemos hoy. El tema aparece en la versión checa del Estudio de Adriana Domínguez Mares ${ }^{6}$ publicado bajo el título Doña Marina - první mexická tlumočnice (Vavroušová et al., 2015, 19-34), que pone énfasis en el estudio de la figura a veces controvertida desde el punto de vista de las características que debe tener una intérprete moderna.

6 Original: Domínguez Mares, A., Doña Marina: primera intérprete mexicana, en: Estudios de Traducción: Problemas y perspectiva (ed. Bravo Utrera, S. et al.), Las Palmas de Gran Canaria 2008, $81-98$. 
La visión del tema sería incompleta sin considerar el papel de los misioneros, quienes en gran medida contribuyeron a la creación de la sociedad latinoamericana actual, tema que desarrolla el trabajo de Martha Pulido Correa ${ }^{7}$, cuyo título checo es Přnos (translace) latinskoamerického léčitelství a několik překladatelských poznámek (Vavroušová et al., 2015, 53-61). Martha Pulido destaca la importancia de mirar la propia historia desde diversos puntos de vista, poniendo énfasis en el papel que tienen los testimonios de las personas que vivieron en aquellas épocas para conocer la propia cultura.

Otra época en la cual la traducción desempeñó un papel cultural sumamente importante es la lucha por la independencia de los pueblos latinoamericanos. Este es el tema del artículo de Lourdes Arencibia Rodríguez ${ }^{8}$, publicado bajo el título Překládání na literárních setkáních v 19. století na Kubě (Vavroušová et al., 2015, 63-78), que pone énfasis en la vida social y cultural de la isla en la época estudiada, las condiciones en que desarrollaban su trabajo los traductores y el papel de la traducción en la divulgación de las diferentes corrientes del pensamiento en la emancipación cultural de la isla.

\subsubsection{El papel social/cultural del traductor/intérprete}

La figura del traductor significa otro aspecto importante para la traductología latinoamericana, en cierta medida inseparable del tema anterior: la importancia la traducción/interpretación en la configuración y emancipación de la(s) cultura(s) latinoamericana(s), eje alrededor del cual se reúnen varios de los aspectos ya antes mencionados.

Un caso emblemático es el estudio de Ricardo Silva-Santiestéban ${ }^{9}$, publicado bajo el título Překladatel Garcilaso de la Vega (Vavroušová et al., 2015, 37-50), texto que, además de volver a reunir lo autóctono y lo importado, arroja luz a un aspecto poco conocido de la vida y creación del patrono de los traductores peruanos.

Otro elemento importante al hablar de la figura del traductor es el nivel de formación general indispensable para que pueda desempeñar su labor. Este es el tema del artículo de Iván Pinto Román ${ }^{10}$, en checo Překládat s vědomím historie (Vavroušová et al., 2015, 95-102), quien ofrece una visión que va desde el traductor practicante, pero

7 Original: Pulido Correa, M.: Apuntes sobre la Translatio en los saberes curativos de América, en: Traductores hispanos de la orden franciscana en Hispanoamérica, (ed. Vega, M. A.), Lima 2012, 63-72.

8 Arencibia Rodríguez, L., La traducción en las tertulias literarias del siglo XIX en Cuba, Hieronymus Complutensis 4-5, 1996/1997, 103-118.

9 Original: Silva-Santiesteban, R., Garcilaso de la Vega el traductor, en: Entre enigmas y certezas: cómo traducir literatura (ed. Valdivia Paz Soldán, R.), Lima 2011, 49-68.

10 Original: Pinto Román, I., Conciencia de la historia en el ejercicio de la traducción, , en: Entre enigmas y certezas: cómo traducir literatura (ed. Valdivia Paz Soldán, R.), Lima 2011, 139-148. 
con formación en otras áreas del conocimiento, a las exigencias que deben cumplir los traductores de la literatura.

Parecido es el tema de la contribución de Daniel Ricardo Yagolkovski ${ }^{11}$, cuya versión checa lleva el título Překlad humoru v literatuře a ve filmu (Vavroušová et al., 2015, 81-92), texto interesante no solo por su contenido, sino también por la visión del tema del otro lado del Atlántico.

\subsection{Conceptos propios de la investigación latinoamericana}

Como ya se ha señalado, la traductología latinoamericana, basada en el estudio de su(s) propias culturas, ha venido desarrollando también sus propios conceptos, entre ellos el de la llamada "traducción cultural», comprendida como el tipo de comunicación intercultural en la que prevalecen los componentes culturales sobre los lingüísticos, que adquiere entre los investigadores latinoamericanos un significado especial. (Vega et al., 2012, 29-50).)

Otro concepto es el del «canibalismo», relacionado ante todo con la investigación brasileña, y comprendido como metáfora de una filosofía cultural, que reúne, entre otros, la absorción de los elementos extranjeros, por una parte, y la resistencia a imitar los elementos e influencias extranjeros en el sentido tradicional de la palabra.

\subsection{Peritextos y metatextos / Recepción por las nuevas generaciones}

Como ya hemos señalado, el objetivo de presentar al público checo los logros de la traductología latinoamericana se ha visto materializado en la publicación de la antología de Vavroušová et al. (2015). La intención de contribuir a llenar las lagunas del conocimiento en esta área se ha visto materializada en la los estudios que acompañan los textos publicados, presentando al público checo tanto a los autores y temas introducidos (Vavroušová 2015b), como a la evolución del pensamiento translativo en las dos áreas lingüísticas latinoamericanas: la hispanohablante y la lusófona.

\subsection{1 Área hispanohablante}

En el estudio dedicado al área hispanohablante (Vavroušová, 2015b) se centra la atención tanto a la evolución de la traducción/interpretación en la evolución cultural, social y política tanto del continente en la época, como en la emancipación de los pueblos que lo componen.

11 Original: Yagolkovski, D. R., Traducción del humor en literatura y en cine, en: Entre enigmas y certezas: cómo traducir literatura (ed. Valdivia Paz Soldán, R.), Lima 2011, 103-118. 
Especial interés recobran las referencias a varios personajes conocidos de otras áreas culturales y sociales: José Martí («...La traducción ha de ser natural, para que parezca como si el libro hubiese sido escrito en la lengua a que lo traduces, -que en eso se conocen las buenas traducciones.» Martí, 1963, 216-220, citado según Vavroušová, 2015b, 15); e Inca Garcilaso de la Vega.

Además, la autora checa ofrece un panorama de las publicaciones más importantes en el área de la historia y teoría de la traducción, publicadas tanto en América Latina como en España, y en último lugar también los principales proyectos de investigación, revistas especializadas y programas universitarios.

\subsection{2 Área lusoparlante (Brasil)}

El estudio dedicado a la traductología brasileña ofrece un breve esbozo de la evolución de Brasil desde el descubrimiento hasta la independencia, la evolución de la traducción relacionada con las diferentes etapas históricas y la institucionalización de los estudios de traducción e interpretación, poniendo énfasis en la metodología propia: el concepto del canibalismo (Laufková, 2015).

Sumamente interesante resultan las huellas centroeuropeas en la evolución de la traductología brasileña: un subcapítulo está dedicado a Paul Rónai (1907-1192), crítico literario, editor, traductor, escritor, filólogo y profesor, quien publicó la primera monografía sobre el tema.

\subsubsection{Aspectos pedagógicos y didácticos}

Como ya se ha señalado, la antología de los estudios traductológicos (Vavroušová et al., 2015) no solo representa el primer intento sistemático de presentar al público checo el pensamiento translativo latinoamericano, sino que es fruto del trabajo de alumnos del doctorado y máster. La necesidad de emprender la traducción de ciertos textos, los traductológicos entre ellos, como un proyecto científico (por ejemplo Behiels, 2013, 90) llevaron a abrir un seminario optativo/taller, donde se debatieron temas como la importancia y la representatividad de los estudios que iban a ser escogidos, partiendo del estudio previo de la historia y teoría de la traducción de los respectivos países y áreas temáticas; se definieron los problemas específicos de la traducción de los respectivos textos (lingüísticos, metalingüísticos, su fuerte intertextualidad, incluidos los aspectos derivados de la ausencia de la tradición doméstica del estudio de los temas incluidos).

La descripción del seminario fue tema de otro estudio (Králová, 2015); sin embargo, el esbozo de la recepción de la traductología latinoamericana en Chequia

sería incompleto sin considerar su efecto multiplicador, que se refleja, entre otros, en 
los recientes trabajos de máster, dedicados al papel de la traducción e interpretación en el descubrimiento y conquista de América y a la función que ha desempeñado la traducción en la configuración de las culturas y sociedades latinoamericanas. ${ }^{12}$

\section{A modo de conclusión}

El estudio del pensamiento translativo suele encontrarse al margen de varias disciplinas, los estudios de las respectivas literaturas y culturas entre ellas. Al tratarse de concepciones poco conocidas fuera de su ámbito lingüístico y cultural, como los estudios latinoamericanos, se destaca el papel de su traducción a otros idiomas para hacerlas accesibles a un público más amplio, contribuyendo de esta forma a superar su marginalidad en el ámbito intelectual en un período en que la traductología busca su renovación metodológica.

El énfasis puesto en la diversificación metodológica de la traductología actual permite confirmar las afirmaciones de otro autor marginado en las teorías universales: Jiří Levý (1971), citado según Králová et al., (2013, 158), quien, refiriéndose a las traducciones literarias, considera el trasvase como una actividad que «estrecha contactos entre las culturas y las enriquece», y continúa:

Una conclusión simplicista podría llevar a la conclusión de que la actividad translativa no es sino un fuerte factor de uniformidad en la literatura.... Es decir, la traducción vuelve a convertirse en una fuerza diferenciadora y unificadora a la vez, porque es preciso considerar no sólo los casos individuales del trasvase, sino también las funciones que desempeña la totalidad del género literario mencionado en el concierto de la cultura actual. (Levý [1971], citado según Králová et al., 2013, 158-159).

Tal vez no sea demasiado audaz afirmar que al incluir la presentación de nuevas concepciones y teorías en el acervo teórico de la investigación nacional se enriquece no solo el conjunto de teorías y metodologías específicas de cierta disciplina, sino que, en caso de conceptos relacionados con la traducción, su adecuada aplicación arroja nueva luz también en la cultura propia.

\section{Bibliografia}

Behiels, L. El traductor como investigador, en: Traducción y humanismo (ed. Bueno García, A. et al.), Bruxelles 2013, pp. 85-98.

12 El creciente interés por esta área en la República Checa se refleja, entre otras actividades, también en la organización del evento «(Trans)missions: Monasteries as Sites of Cultural Transfers» en septiembre 2017 y en las memorias del máster, preparadas actualmente en el Instituto de Traductología de la Facultad de Filosofía y Letras, Universidad Carolina. 
Borges, J. L., Homérovské př̀klady, en: Překlad literárního díla (ed. Čermák, J. et al.), Praha 1970, pp. 279-284.

Housková, M., Univerzální pluralita: překlad v myšlení O. Paze, Svět literatury 38, 2008, pp. 169-172.

Housková, M., O básnickém řemesle Jorge Luise Borgese, 2005, www.iliteratura.cz /17909/ [8. 6. 2017].

Králová, J., La presencia de la traducción y de la lingüística misioneras en el aula: experiencia didáctica, Mutatis Mutandis 8/1, 2015, pp. 163-180.

Králová, J. et al., Jiří Levý: una concepción (re)descubierta, Soria 2013.

Kšicová, D., Poetika uměleckého překladu, Opera slavica XXI, 2011, pp. 1-6.

Lambert, J., The Languages of Translation. Keys to the Dynamics of Culture, en: Translation and Cultural Identity: Selected Essays on Translation and Cross-cultural Communication (ed. Muñoz-Calvo, M. et al.) Newcastle 2010, pp. 33-60.

Laufková, P., Vývoj a současný stav translatologie v Brazílii aneb brazilský teoretik překladu není lidojed, en: Překlad a tlumočení jako most mezi kulturami (ed. Vavroušová, P. et al.), Praha 2015, pp. 103-112.

Levý, J., Umění překladu, Praha 1963.

Levý, J., Bude literární věda exaktní vědou, Praha 1971.

Martí, J., Obras completas XX, La Habana 1963.

Pulido, M., La traducción de la historia de la traducción en la formación de traductores, en: Posibilidades y límites de la comunicación intercultural (ed. Králová, J.), Praha 2011, pp. 85-96.

Svět literatury, http://sl.ff.cuni.cz [13. 9. 2017].

Šišmišová, P., Vklad J. L. Borgesa do disikusií o preklade, Svět literatury 48, 2012, pp. $173-182$.

Vavroušová, P. et al., Překlad a tlumočení jako most mezi kulturami. Praha 2015.

Vavroušová, P., Překlad a tlumočení jako most mezi kulturami, en: Překlad a tlumočení jako most mezi kulturai (ed. Vavroušová, P.), Praha 2015a, pp. 7-12.

Vavroušová, P., Vývoj a současný stav translatologie v Latinské Americe (španělsky mluvící část) aneb dobývání Translachtitlánu, en: Překlad a tlumočení jako most mezi kulturami.(ed. Vavroušová, P.), Praha 2015b, pp. 13-18.

Vega Cernuda, M. Á., et al., Traductores hispanos de la orden franciscana en Hispanoamérica. Lima 2012.

Zimmermann, K., Translation for colonization and christianization, en: Misonary linguistics V(ed. Zwartjes, O. et al.), Amsterdam 2014, pp. 85-111. 
Jana Králová

\section{Recepcija latinskoameriškega prevodoslovja na Češkem: tematski, metodološki in didaktični vplivi}

Ključne besede: prevodoslovje, medkulturna komunikacija, metodologija, kulturno prevajanje, kanibalizem

$\mathrm{V}$ zadnjih letih se je prevodoslovje posvečalo iskanju metodološke prenove na do nedavnega marginalnih in marginaliziranih jezikovnih in kulturnih področjih. Kot primer lahko vzamemo latinskoameriško prevodoslovje, ki je od posluževanja evropskih pojmovanj prešlo k razvijanju lastnih tem (npr. misijonarsko prevajanje) in metodologij (koncept »kulturnega prevajanja«, »kanibalizem«), ki odpirajo nove poti tudi na področju izobraževanja prevajalcev, tolmačev in drugih strokovnjakov medkulturne komunikacije, zgodovine kultur itd. Študija strni recepcijo latinskoameriških pojmovanj prevajanja, pa tudi njihovo didaktično rabo, $v$ raziskovalnih krogih na Češkem. 
Jana Králová

\section{Reception of Latin-American translation studies in Czechia: conceptual, methodological and didactic inspirations}

Keywords: translation studies, intercultural communication, methodology, cultural translation, cannibalism

In recent years translation studies has been in search of methodological innovations in the linguistic and culture spheres that have so far remained unexplored. For example, the discipline of Latin-American translation studies has seen a transition from the application of European-based methodology to focusing on local topics, like missionary translation, for example, as well on the integration of domestic methodology conceptualized as cultural translation or cannibalism, and opening new vistas to translator and interpreter training, to exploration of intercultural communication, cultural history and so forth. This study presents a summary of the reception of such Latin-American concepts by Czech translation scholars, including didactic application. 